\title{
Dimensionamento de Biodigestores Indiano para a cidade de Campina Grande
}

Maria Isabel do Bú Araújo* (Graduanda em Engenharia Química na Universidade Federal de Campina Grande-UFCG);

Adalício Uzêda Antunes Júnior (Mestrando em Engenharia Química na Universidade Federal de Campina Grande -UFCG);

Fernanda Siqueira Lima (Graduanda em Engenharia Química na Universidade Federal de Campina Grande-UFCG);

José Mariano da Silva Neto (Graduando em Engenharia Química na Universidade Federal de Campina Grande-UFCG).

*isabel_dobu@hotmail.com

Resumo:

A busca por novas tecnologias que venham a substituir as fontes de energia não renováveis, suprindo as necessidades energéticas e também cuidando do meio ambiente, estão intensificadas devido à preocupação mundial com esses fatores.

A utilização de resíduos indústrias, agrícolas e urbanos para a obtenção de energia tem ganhado destaque em meio a esses novos estudos. E uma das formas mais visadas e aplicadas são os Biodigestores, que são equipamentos que aliam a produção de energia, tratamento de resíduos e a produção de biofertilizantes. Fazendo o uso energético do gás metano, proveniente da digestão anaeróbica dos resíduos, cujo potencial de aquecimento global (efeito estufa) é 21 vezes maior que o do gás carbônico.

O dimensionamento de um biodigestor requer o conhecimento prévio de alguns fatores, dentre eles a produção da biomassa a ser encaminhada ao biodigestor, que vem a ser o principal fator a ser considerado. Para o caso em estudo obteve-se os dados da cidade de Campina Grande em relação ao número de habitantes e ao lixo orgânico produzido diariamente, a fim de dimensionar um biodigestor do tipo Indiano que venha a suprir as necessidades da cidade em estudo.

Pallavras-chave:

Biodigestor indiano; Produção de Biogás; Tecnologia alternativa. 


\section{I ntrodução}

A demanda por inovações tecnológicas que venham a suprir a produção energética mundial vem crescendo, devido a crise nas tecnologias não renováveis que vem se tornando a cada dia mais escassas para a demanda mundial. O Brasil, assim como os demais países, vem investido nessa substituição, como é o caso das pesquisas com álcool e biocombustíveis. Porém, outra fonte energética que vem ganhado espaço e se mostrando favorável é a biomassa para a produção do biogás, que tem seu uso desde o âmbito domestico ao âmbito industrial.

A matéria prima para essa produção de biogás é a biomassa que pode ser resíduos industriais, urbanos ou agrícolas. Ela passa por um processo de digestão anaeróbica e como produto se obtém o biogás e o biofertilizante, esse processo ocorre em equipamentos denominados biodigestores, que diferem entre si devido a capacidade de produção, as condições climáticas aos quais são submetidos e ao seu objetivo final, podendo ser de pequeno ou grande porte, operar de forma contínua ou batelada.

Através da digestão anaeróbia o principal gás obtido é o metano que pode constituir até $70 \%$ do biogás. O gás metano é incolor, apresenta elevado poder calorífico (5000 - 7000 kcal m3), altamente combustível, não produz fuligem, e o impacto de efeito estufa é 21 vezes maior do que o dióxido de carbono. A quantidade de metano obtido varia de acordo com a quantidade, o tipo de biomassa, clima, e dimensão do biodigestor. A Tabela 1 apresenta a composição do biogás (FLORES,2014).

Tabela 1 - Composição do biogás

\begin{tabular}{c|c}
\hline Composição & $\%$ \\
\hline Metano $\left(\mathrm{CH}_{4}\right)$ & $50-70$ \\
\hline Dióxido de Carbono $\left(\mathrm{CO}_{2}\right)$ & $25-50$ \\
\hline Nitrogênio $\left(\mathrm{N}_{2}\right)$ & $0-7$ \\
\hline Gás Sulfídrico $\left(\mathrm{H}_{2} \mathrm{~S}\right)$ & $0-3$ \\
\hline Oxigênio $\left(\mathrm{O}_{2}\right)$ & $0-2$ \\
\hline Hidrogênio $\left(\mathrm{H}_{2}\right)$ & $0-1$ \\
\hline Amoníaco $\left(\mathrm{NH}_{3}\right)$ & $0-1$ \\
\hline Monóxido de Carbono $(\mathrm{CO})$ & $0-0.2$ \\
\hline Fonte: CETESB $(2011)$ &
\end{tabular}

Após a passagem pelo digestor, o resíduo torna-se um excelente fertilizante, rico em nitrogênio e húmus, ótimo adubo para fins agrícolas. Na Tabela 2 é apresentada a composição do biofertilizante.

Tabela 2 - Composição do biofertilizante

\begin{tabular}{c|c}
\hline Composição & $\%$ \\
\hline Nitrogênio (N2) & $1,4-1,8$ \\
\hline Fosfato (PO4) & $1,1-2,08$ \\
\hline Oxido de Potássio (K2O) & $0,8-1,28$ \\
\hline \multicolumn{2}{c|}{ *esses valores são validos após a secagem da pasta. }
\end{tabular}

O biodigestor Indiano foi o primeiro a ser idealizado em meados de 1857 em Bombain na Índia. O biodigestor indiano distingue-se por possuir uma campânula como gasômetro, a qual pode estar mergulhada sobre a biomassa em fermentação, ou em um selo d'água externo, e uma parede central que divide o tanque de fermentação em duas câmaras. A função da parede divisória faz com que o material circule por todo o interior da câmara de fermentação. O modelo indiano possui pressão de operação constante, ou seja, à medida que o volume de gás produzido não é consumido de imediato, o gasômetro tende a deslocar-se verticalmente, aumentando o volume deste, portanto, mantendo a pressão no interior deste constante. $\mathrm{O}$ fato de o gasômetro estar 
disposto ou sobre o substrato ou sobre o selo d'água, reduz as perdas durante o processo de produção do gás (DEGANUTTI et al , 2009).

O resíduo a ser utilizado para alimentar o biodigestor indiano, deverá apresentar uma concentração de sólidos totais (ST) não superior a 8\%, para facilitar a circulação do resíduo pelo interior da câmara de fermentação e evitar entupimentos dos canos de entrada e saída do material. Do ponto de vista construtivo, apresenta-se de fácil construção, contudo o gasômetro de metal pode encarecer o custo final, e também à distância da propriedade pode dificultar e encarecer o transporte inviabilizando a implantação deste modelo de biodigestor. A Figura 1, mostra o biodigestor, realçando os elementos fundamentais para sua construção.

Figura 1 - Biodigestor Indiano

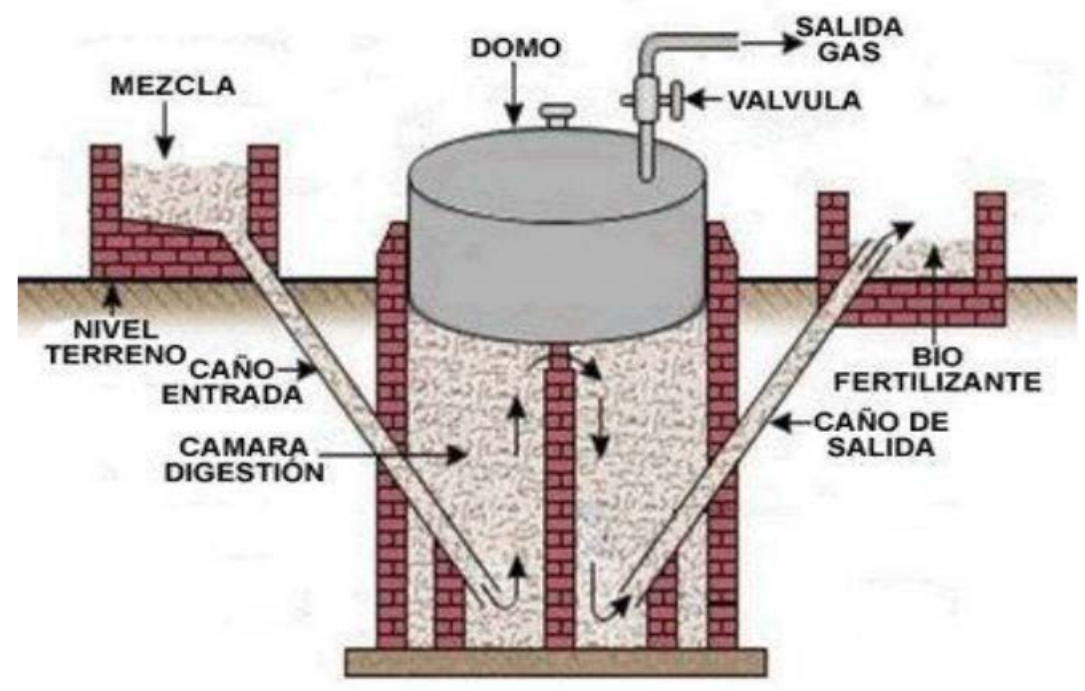

\section{Objetivos}

\subsection{Objetivo Geral}

Este trabalho tem como objetivo obter as dimensões reais de um biodigestor do tipo Indiano que supra a necessidade da cidade de Campina Grande.

\subsection{Objetivos Específicos}

- Dimensionar o cano de carga;

- Dimensionar o cano de Descarga;

- Dimensionar o Tanque de Carga e Descarga;

- Dimensionar o cano guia;

- Dimensionar o selo d'água;

- Parede divisória de fases;

- Volume do gasômetro;

- Volume do biodigestor.

\section{Metodologia para dimensionamento do Biodigestor I ndiano para a cidade de Campina Grande}


O município de Campina Grande/PB, com base na última estimativa do Instituto Brasileiro de Geografia e Estatística - IBGE, efetuada em 01 de julho de 2014, tem uma população de 402.912 habitantes, sendo o segundo município em população do Estado, representando grande influência política e econômica sobre as cidades adjacentes.

Conforme os dados do último PNSB - Pesquisa Nacional sobre Saneamento Básico, realizado pelo Instituto Brasileiro de Geografia e Estatística - IBGE, em 2000[i], o município de Campina Grande/PB detém 90,8\% da coleta dos resíduos domiciliares, o remanescente são queimados (2.6\%), enterrados (0.4\%), despejados em terrenos baldios (5.5\%), em rios ou lagos $(0.3 \%)$ e outras formas $(0.3 \%)$.

O sistema de limpeza urbana normalmente tem seu desfecho logo após a coleta, sem a aplicação de nenhum processo que visa um beneficiamento, os resíduos coletados são apenas descartados sem nenhum aproveitamento. Porém, em alguns casos antes do descarte o lixo sofre um processo, no qual ocorre uma melhora, podendo assim obter resultados econômicos, sanitários e ambientais positivos.

Como o município de Campina Grande/PB, não possui aterro sanitário, que seria a forma mais adequada para a destinação dos resíduos produzidos na cidade, nem de outras maneiras de acondicionamento para estes resíduos, os quais são despejados a céu aberto no Lixão do Mutirão pertencente à Prefeitura Municipal, localizado na Alça Sudoeste da cidade, a uma distância de 8.0 km do centro urbano, com uma área total de 35 hectares. Neste local não é realizado nenhum tipo de controle prévio do que é lançado, e não existe nenhuma precaução em relação à saúde pública, além do descaso para com a população que sem opções de moradia e fonte de renda acabam se instalando no do próprio lixão.

Nesse contexto, propõem-se aproveitar a matéria orgânica produzida pelos moradores da cidade de Campina Grande visando diminuir os impactos ambientais, sendo, portanto, uma unidade de geração de bioenergia uma alternativa viável para essa problemática.

Considerando que a cidade de Campina Grande, Paraíba, possui 402.912 habitantes e que cada habitante produz em média 700 gramas de lixo orgânico por dia, teremos uma quantidade diária de 282.038,4 kilogramas. Nesse contexto o sistema deverá ser projetado para suprir a necessidade diária do município.

Para a produção do biogás é necessário homogeneizar a biomassa com água, que deve ser adicionada a uma proporção que varie de 10 a 50\% em razão mássica a depender do tipo de biodigestor utilizado.

A produção de biogás é função também da quantidade de biomassa, razão biomassa/água, varia de 10 a 50\% em razão mássica a depender do tipo de biodigestor utilizado, tempo de residência, custos das instalações, custos operacionais, produção e aplicação do biogás e aplicação do biofertilizante. De acordo com Carneiro (2007) são necessários 20 kg de lixo para a produção de $1 \mathrm{~m}^{3}$ de biogás.

Os resíduos sólidos urbanos provenientes do município de Campina Grande, Paraíba, serão recebidos para inicialmente uma triagem manual e após isso um pré-tratamento para o posterior envio para os biodigestores para a produção do biogás e biofertilizante.

Todo projeto de implantação de biodigestores tem como condição elementar o dimensionamento de tal equipamento. Segundo o dicionário Aurélio, dimensionar significa fixar as dimensões de uma peça a fim de que ela desempenhe o seu papel no conjunto de que faz parte.

De acordo com Lucas Junior e Souza (2009), os principais componentes de um biodigestor modelo indiano são:

a) caixa de carga (local de diluição dos dejetos);

b) tubo de carga (condutor dos dejetos diluídos da caixa de carga para o interior do biodigestor);

c) câmara de biodigestão cilíndrica (local onde ocorre a fermentação anaeróbia com produção de biogás);

d) gasômetro (local para armazenar o biogás produzido formado por campânula que se movimenta para cima e para baixo);

e) tubo-guia (guia o gasômetro quando este se movimenta para cima e para baixo);

f) tubo de descarga (condutor para saída do material fermentado sólido e líquido); 

líquido);

g) caixa ou canaleta de descarga (local de recebimento do material fermentado sólido e

h) saída de biogás (dispositivo que permite a saída do biogás produzido para ser encaminhado para os pontos de consumo).

A Figura 2 apresenta o desenho esquemático do biodigestor indiano e sua descrição.

Figura 2 - Desenho esquemático do Biodigestor Modelo Indiano

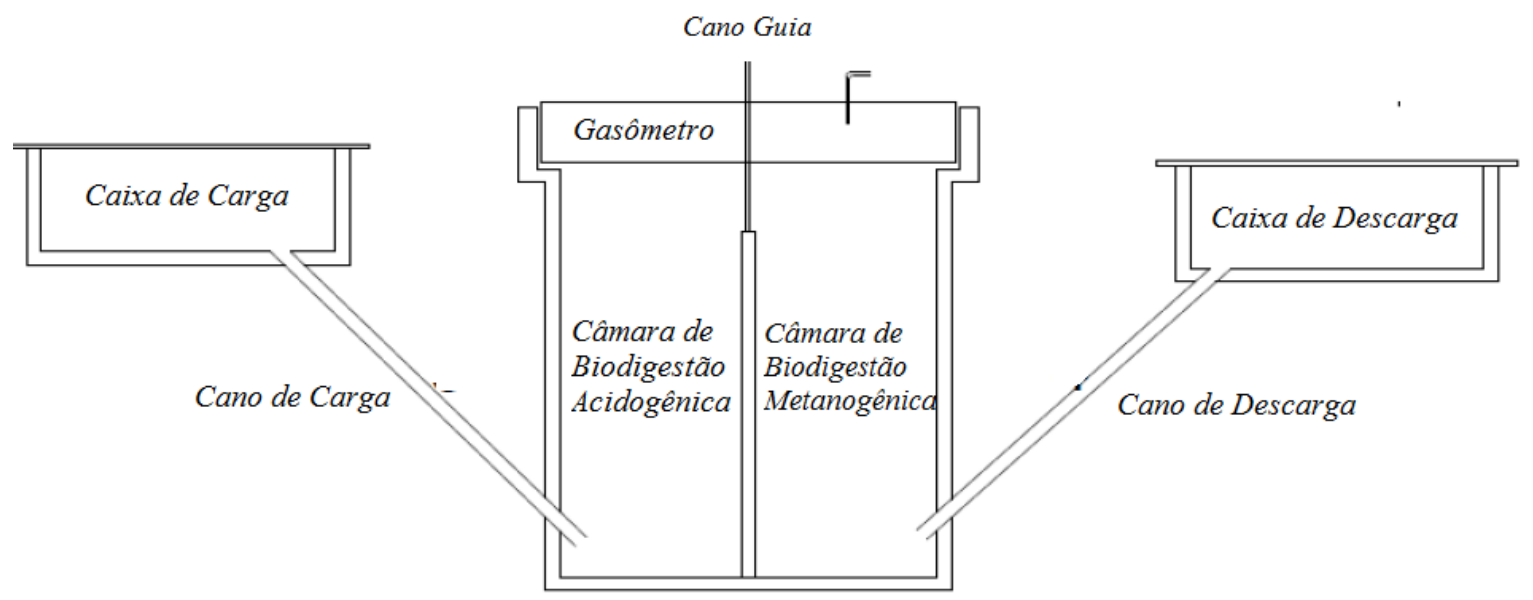

Segundo Biodieselbr (2009), um método prático de estimular o tamanho do biodigestor é dado pela fórmula abaixo:

$\mathrm{VB}=\mathrm{VC} \times \mathrm{THR}$

Equação (1)

Onde:

$\mathrm{VB}=$ Volume do biodigestor (m3);

VC = Volume da carga diária (m3/dia)

THR $=$ Tempo de retenção hidráulico (dias)

\section{Resultados}

\subsection{Volume do biodigestor}

Utilizando a Equação 1, é possível calcular o volume do biodigestor, em que o volume da carga diária é igual a 1221,0 m³/dia, os tempos de retenção hidráulica iguais a 1 e 4 dias, para a fase acidogênica e metanogênica, respectivamente. Logo,

$$
\begin{gathered}
\mathrm{VB}=\mathrm{VC} \times \mathrm{THR} \\
\mathrm{VB}=1221 \times 5 \\
\mathrm{VB}=6.105,0 \mathrm{~m}^{3}
\end{gathered}
$$

Por ser tratar de um grande volume, o que dificultaria a sua construção, essa unidade constará de 6 biodigestores indiano e cada um terá um volume de 1017,5 $\mathrm{m}^{3}$. Sendo subdivido em 203,5 $\mathrm{m}^{3}$ a câmara acidogênica e $814,0 \mathrm{~m}^{3}$ a câmara metanogênica. 
Para se calcular as dimensões do biodigestor, ou seja, sua altura (H) e seu diâmetro (D), utilizou-se a Equação 2, em que $V=V B$.

$V=\frac{\pi D^{2}}{4} x H$

Equação (2)

É importante citar que existe uma faixa ótima aceitável para a relação D/H. Para o caso estudado, visto que trata-se de um grande biodigestor, volume maior que $10 \mathrm{~m}^{3}$, essa razão deve ser igual a 1. Com esse valor é possível proporcionar uma maior eficiência de fermentação e também evita com que a altura não dificulte a escavação. Os valores utilizados para o diâmetro e a altura foram de 10,9.

A altura $\mathrm{H}=10,9 \mathrm{~m}$ é denominada de altura útil, $\mathrm{Hu}$, ou seja, aquela que confere ao cilindro o volume planejado. Porém, devemos determinar a altura real, $\mathrm{Hr}$, que é calculada adicionando-se a altura útil o equivalente ao desnível decorrente da pressão $\mathrm{P}$, mais $0,1 \mathrm{~m}$ para evitar o transbordamento da mistura, em decorrência de agitação ou turbulência durante 0 carregamento. Para esse tipo de biodigestor é fixado um acréscimo de $0,25 \mathrm{~m}$. Assim a altura real será igual a $11,15 \mathrm{~m}$.

\subsection{Volume do gasômetro}

De acordo com Carneiro (2007) são necessários 20 kg de lixo para a produção de $1 \mathrm{~m}^{3}$ de biogás. Com isso o volume de biogás gerado por dia será de 14.101,92 $\mathrm{m}^{3}$ sendo que cada biodigestor produzirá em média $2351 \mathrm{~m}^{3}$. Com isso pode-se utilizar a fórmula do volume do cilindro para se calcular as dimensões. No caso específico, o valor do diâmetro do gasômetro, Dg, está condicionado ao diâmetro do próprio biodigestor. O diâmetro do gasômetro pode ser calculado a partir da Equação 3.

$\mathrm{Dg}=\mathrm{Di}+2 \mathrm{~L}+0,10$

Equação (3)

Onde:

Di = diâmetro do biodigestor;

Di = diâmetro do biodigestor;

$\mathrm{L}=1,20 \mathrm{~m}$

Assim, $\mathrm{Dg}=13,40 \mathrm{~m}$

O valor do diâmetro do gasômetro foi de $13,40 \mathrm{~m}$ e a altura útil igual a 16,60 m. Determinada a altura útil do gasômetro, foi calculada a altura real do gasômetro (Hrg), considerando as mesmas condições do volume do biodigestor, sendo Hrg = 16,85 m.

\subsection{Parede divisória de fases}

A parede divisória divide o cilindro de cada biodigestor em duas subcâmaras. Possuindo largura igual ao diâmetro interno e espessura igual a 0,1m, que é a largura do tijolo utilizado. A altura da parede divisória pode ser calculada através da Equação 4.

$\mathrm{Hp}=\mathrm{Hrg}-\mathrm{Hr}$

Equação (4)

Onde:

Hp = altura da parede;

$\mathrm{Hr}=$ altura real do biodigestor.

Hrg = altura real do gasômetro;

Logo, Hp = 5,45 m.

\subsection{Dimensões do selo d'água}


O selo d'água é composto por três partes: parede interna, fosso e parede externa.

Parede interna: separa a água do selo (fosso) da mistura da fermentação. Esta parede apresenta uma espessura igual à largura do tijolo $(0,15 \mathrm{~m})$ e altura igual à altura do gasômetro Hrg.

Fosso: é o espaço entre as duas partes do selo d'água, onde o gasômetro se movimenta em contato com a água, a qual impede a liberação do biogás. Esse espaço tem dimensão de 0,20 $\mathrm{m}$ de largura.

Parede externa: fecha externamente o fosso. Apresenta uma espessura igual à largura do tijolo e altura $0,10 \mathrm{~m}$ mais baixa que a parede externa, a fim de evitar que a água da chuva transborde para dentro do biodigestor.

\subsection{Dimensões do cano guia}

A função do cano guia é orientar o deslocamento do gasômetro. O comprimento desse cano é determinado pela Equação 5.

$\mathrm{Cg}=1+\mathrm{Hrg}+\frac{\mathrm{Hrg}}{2}$

Equação (5)

Onde,

$\mathrm{Cg}$ = comprimento do cano guia.

Assim, $\mathrm{Cg}=1+16,6+\frac{16,6}{2}=25,9 \mathrm{~m}$

\subsection{Dimensionamento do Tanque de Carga e Descarga}

O tanque de carga e descarga deve apresentar um volume capaz de armazenar as cargas diárias do município. As suas dimensões são determinadas pela fórmula de volume de um cubo. É importante observar a relação das dimensões para que não tenham valores com grande disparidade, à altura não deve ser superior a $1,20 \mathrm{~m}$ para não dificultar o manuseio do resíduo, foram considerados $0,10 \mathrm{~m}$ à altura das caixas para evitar trasbordamento, sendo vedadas com uma tampa móvel para a maior segurança do biodigestor.

As dimensões de cada tanque de carga e descarga são $30 \mathrm{~m}$ de largura, $35 \mathrm{~m}$ de comprimento e 1,2 m de altura, sendo capaz de armazenar a carga de um dia de coleta de resíduos da cidade, caso o biodigestor precise de manutenção ou algum reparo em sua estrutura.

\subsection{Dimensionamento do cano de Descarga}

O cano de descarga "Cd" tem início a 0,50 m do fundo da segunda subcâmara, sua extremidade superior encontra-se no nível da parede externa do selo d'água, a distância da parte superior do cano para a parede externa do selo d'água deve ser de 0,50 a 1,00 m para facilitar a movimentação do operador em volta do biodigestor. Considerando o triangulo retângulo formado pelo cano de descarga "Cd" (hipotenusa), altura real do biodigestor "Hr" - 0,60m (cateto) e afastamento do cano de descarga do biodigestor (cateto), pode se determinar o comprimento do cano Cd pela Equação 6.

$\mathrm{Cd}=\sqrt{(\mathrm{Hr}-0,6)^{2}+1,6^{2}}$

Equação (6)

O comprimento encontrado para o cano de descarga foi de 10,67 m.

\subsection{Dimensionamento do cano de carga}

O cano de carga "Cdg" tem início no fundo do tanque de carga e desemboca a 0,50 m do fundo da primeira subcâmara. A distância do tanque de carga até o biodigestor deve ser igualmente a do cano de descarga de 0,50 a $1,00 \mathrm{~m}$. O fundo do tanque de carga, ou seja, a parte superior do cano de carga deve estar no mínimo no nível da extremidade superior do cano de descarga, uma vez que a introdução do resíduo se dá pelo princípio dos vasos comunicantes. 
Para a obtenção do comprimento do cano de carga “Cdg” usou-se a Equação 7:

$\mathrm{Cdg}=\mathrm{Cd}+0,2$

Ou seja, o comprimento do cano de carga do projeto atual é de 10,87 m.

Equação (7)

\section{Considerações finais}

Para a construção de um biodigestor que venha a suprir a necessidade da cidade de Campina Grande, carga diária 1221,0 m³/dia, é necessária, portanto a construção de uma unidade que constará de 6 biodigestores indiano com volumes individuais de $1017,5 \mathrm{~m}^{3}$. Sendo subdivido em 203,5 $\mathrm{m}^{3}$ a câmara acidogênica e 814,0 $\mathrm{m}^{3}$ a câmara metanogênica.

Para a próxima etapa do projeto tem-se o estudo da viabilidade da construção da unidade completa, juntamente com a proposta de alternativas secundárias que venham a balancear 0 tratamento dos resíduos gerados pelos habitantes da cidade.

\section{Design of Indian Biodigesters to the city of Campina Grande}

Albstract: The search for new technologies that will replace the non-renewable sources of energy, meeting energy needs and also taking care of the environment are intensified due to the global concern for these factors.

The use of waste industries, agricultural and urban for obtaining energy has gained prominence among these new studies. One of the most targeted and applied forms are the biodigesters, which are devices that combine energy production, waste treatment and production of bio-fertilizers. Making energy use of methane gas from the anaerobic digestion of waste, whose global warming potential (greenhouse) is 21 times greater than that of carbon dioxide.

The design of a digester requires prior knowledge of certain factors, including the production of biomass to be sent to the digester, which becomes the main factor to be considered. For the work, it was utilized the data from the city of Campina Grande related with the number of inhabitants and the organic waste produced daily in order to design a biodigester Indian type that will meet the city's needs in study.

Keywords: Indian Biodigester; Biogas production; Alternative technology.

\section{Referências bibliográficas}

BUREN, A. V., Crook, M. A Chinese Biogas Manual. Intermediate Technology Publications, Ltd., London, UK, 1979.

CARnEIRO, J.V. Produção de Gás Metano em Biodigestor. Monografia. 2007. 45 paginas.

CETESB - SECRETARIA DO MEIO AMBIENTE DE SÃO PAULO. Biogás. Disponível em: http://homologa.ambiente.sp.gov.br/biogas/biogas.asp> .Acesso em 23 Maio de 2015.

DEGANUTTI, R., PALHACI, M. do C. J. P., ROSSI, M.. Biodigestores rurais: modelo indiano, chinês e batelada. In Anais do $4^{\circ}$ Encontro de Energia no Meio Rural, Campinas (SP), 2002.

DOS SANTOS, E.L.B., JUNIOR, G.N. Produção de Biogás a Partir de Dejetos de Origem Animal. Tekhne e Logos, Botucatu, SP, v.4, n.2, Agosto, 2013. ISSN 2176 - 4808

FLORES, M.C. Viabilidade econômica do biogás produzido por biodigestor para produção de energia elétrica - estudo de caso em confinador suíno./ Marcelo Costa Flores; Orientação 
de Marcos Vinicius Rodrigues. Poços de Caldas: 2014. 32 fls.: il.; 30 cm. Inclui bibliografias: fls. 31-32

IBGE, Fundação Instituto Brasileiro de Geografia e Estatística. Censos Demográficos 2014. Disponível em: < http://www.ibge.gov.br>. Acesso em: 23 de maio de 2015.

JÚNIOR, B. C. Embrapa - Agroenergia da biomassa residual: perspectivas energéticas, socioeconômicas e ambientais. 2. ed. Foz do Iguaçu: FAO. 2009.

MINISTÉRIO DO MEIO AMBIENTE. Guia para elaboração dos Planos de Gestão de Resíduos Sólidos. 289 páginas. 2011.

PNSB, Pesquisa Nacional de Saneamento Básico- PNSB de 2000. Disponível em: $<$ http://www.ibge.gov.br >. Acesso em: 23 de maio de 2015.

SGANZERLA, E. Biodigestor, uma solução. Porto Alegre, RS, 1983. 